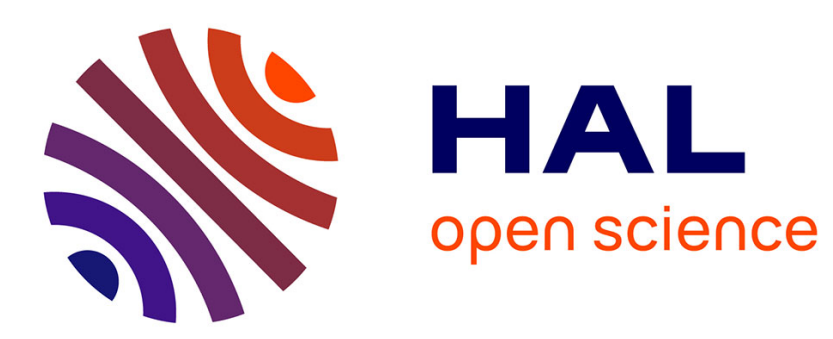

\title{
Attempt of the Metallic 3D Printing Technology for Millimeter-Wave Antenna Implementations
}

Bing Zhang, Peter Linnér, Camilla Kärnfelt, Pui Lam Tam, Ulf Södervall, Herbert Zirath

\section{- To cite this version:}

Bing Zhang, Peter Linnér, Camilla Kärnfelt, Pui Lam Tam, Ulf Södervall, et al.. Attempt of the Metallic 3D Printing Technology for Millimeter-Wave Antenna Implementations. APMC 2015: AsiaPacific Microwave Conference, Dec 2015, Nanjing, China. pp.1 - 3, 10.1109/APMC.2015.7413011 . hal-01299334

\section{HAL Id: hal-01299334 \\ https://hal.science/hal-01299334}

Submitted on 7 Apr 2016

HAL is a multi-disciplinary open access archive for the deposit and dissemination of scientific research documents, whether they are published or not. The documents may come from teaching and research institutions in France or abroad, or from public or private research centers.
L'archive ouverte pluridisciplinaire HAL, est destinée au dépôt et à la diffusion de documents scientifiques de niveau recherche, publiés ou non, émanant des établissements d'enseignement et de recherche français ou étrangers, des laboratoires publics ou privés. 


\title{
Attempt of the Metallic 3D Printing Technology for Millimeter-Wave Antenna Implementations
}

\author{
Bing Zhang ${ }^{1}$, Peter Linnér ${ }^{1}$, Camilla Kärnfelt ${ }^{2}$, Pui Lam Tam ${ }^{1}$, Ulf Södervall ${ }^{1}$, Herbert Zirath ${ }^{1}$ \\ ${ }^{1}$ Chalmers University of Technology, Gothenburg SE-41296, Sweden; ${ }^{2}$ Microwave Department of Télécom \\ Bretagne-Institute Mines-Télécom, Brest, France \\ Email: bing.zhang@chalmer.se
}

\begin{abstract}
D metallic printing technology is attempted to implement millimeter-wave (mmWave) antennas. Based on laser beam melting (LBM) technology, the cost and turnaround time of metallic horn antenna fabrication is effectively reduced compared with traditional milling and injection moulding. A conical and a pyramidal horn antenna are printed in $316 \mathrm{~L}$ stainless steel, both of which demonstrate satisfactory performance compared with simulation, as well as comparable performance with commercial horn antennas. Surface roughness of the printed horn antennas are measured and analyzed, showing improvement upon former designs. The 3D printing technology proves its great potential for further exploration.
\end{abstract}

Index Terms - 3D printing, conical horn antenna, pyramidal horn antenna, surface roughness, V-band.

\section{INTRODUCTION}

The concept of 3D printing, also identified as additive manufacturing, was first visible in 1980's which was originally named as rapid prototyping (RP). Throughout the 1990's and 2000's, a host of new technologies continued to be introduced that focused on mechanical applications. Simultaneously, the 3D-printing technology found its broad applications in the area of medical treatment, aerospace, automotive and architectures for the merits of low cost manufacturing, quick production, eco-friendly with reduced carbon footprint, versatile with new structures and flexible combination of different materials. For example, NASA introduced a 3D printer in space to assist astronauts in producing parts and tools in zero gravity. Companies like GE, Airbus, Rolls-Royce and Boeing also invested their effort in the development of 3D printing technology. However, reports on the application of 3D printing in the millimeter-wave (mmWave) range are rare [1] [2].

In mmWave system, the antenna is an essential part. The mmWave antennas are categorized as on-chip and off-chip antennas. The on-chip antennas are implemented by monolithic microwave integrated circuit (MMIC) process on thin semiconductor or organic substrates like benzocyclobutene (BCB). They feature easy integration with the system, however the low efficiency is the drawback. The on-chip antennas are subdivided as planar antennas and horn antennas in a broad sense, both of which have higher efficiency than the off-chip counterparts but bulky profile. Examples of planar antennas can be found on LTCC [3-6], LCP, Duroid and PTFE. For horn antennas, the traditional implementation is by machining or injection moulding. The milling is a subtractive process which results in a large amount of wasted metal scraps. The injection moulding is more environment-friendly, but the turnaround time and cost are not acceptable for costumed designs in a small volume. For this application, the $3 \mathrm{D}$ printing technology seems to be a good choice that almost overcomes all the drawbacks of traditional methods. Polymer 3D printing technology has been used to implement horn antennas below mmWave frequency [7]. The surfaces of the antenna are then metal-plated after printing. Though tested with acceptable performance, life-cycle of the polymer 3D printing antenna is quite limited because of the fragility of polymer, especially for the screw thread in the flange. Metallic 3D printing has also been attempted at $\mathrm{Ku}$-band, in which the surface roughness heavily influences the antenna's performance [8].

In this paper, we succeed to use the metallic 3D printing technology to implement V-band $(50-75 \mathrm{GHz})$ conical and pyramidal horn antennas for the first time. Surface roughness of the antennas are significantly improved upon former reported cases at low frequency [8]. Good agreement between the simulated and measured performance prove the great potential of $3 \mathrm{D}$ printing technology for $\mathrm{mmWave}$ applications.

\section{DESIGN AND FABRICATION}

A conical and a pyramidal horn are designed. The conical horn has an aperture diameter of $22 \mathrm{~mm}$, horn length of $37 \mathrm{~mm}$, and a $10 \mathrm{~mm}$ rectangular WR-15 $(3.8 \mathrm{~mm} \times 1.9 \mathrm{~mm})$ waveguide feed from the flange. Discontinuity from the rectangular waveguide to the conical horn gives rise to reflection at the input port. A taper is usually applied between the rectangular waveguide and the horn. In this paper, to simplify the design, a $10 \mathrm{~mm}$ rectangular feeding waveguide is directly connected to the horn. Screw thread and alignment holes are made by post process. Fig. 1 (a) - (c) show photographs of the printed horns in $316 \mathrm{~L}$ stainless steel in profile view, aperture view and flange view. The flaw and unsmoothness on the flange in Fig. 1 (c) can be grinded.

A pyramidal horn is also printed in $316 \mathrm{~L}$ stainless steel for comparison. It has aperture dimensions of $19.2 \times 14.56 \mathrm{~mm}^{2}$, horn length of $35 \mathrm{~mm}$ and a feeding WR-15 waveguide of 10 $\mathrm{mm}$ length. Screw thread and align holes are implemented by a post process. Fig. 2 (a) - (c) show the photographs of the pyramidal horn in profile view, aperture view and flange view.

Apparent surface roughness is observed both in the conical horn and pyramidal horn, which results in increased sheet resistance of the inner surface of the horn, and thus decreased antenna gain. Moreover, the random scattering from the rough 
surface may also increase the level of cross-polarization. The inner surface of the printed horn antennas are investigated by a stylus profilometer at room temperature. Fig. 3 shows the surface roughness of $\mathrm{Ra}=7.7 \mu \mathrm{m}$ with $1.3 \mu \mathrm{m}$ standard deviation, which is obtained from the average of four repeated measurements. The influence of the surface roughness is reflected by the disagreement between simulated and measured performance in Fig. 4 and 5.

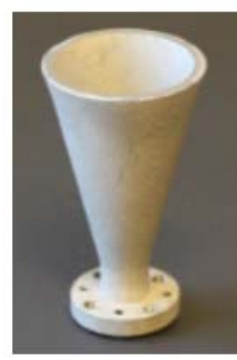

(a)

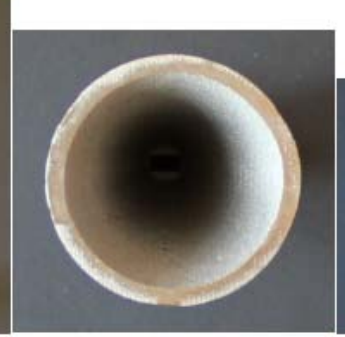

(b)

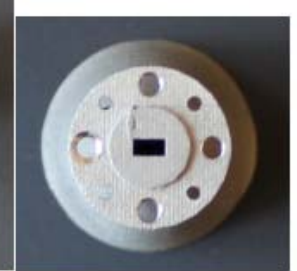

(c)
Fig. 1. Photographs of the 3D printing conical horn antenna: (a) profile view, (b) aperture view and (c) flange view.

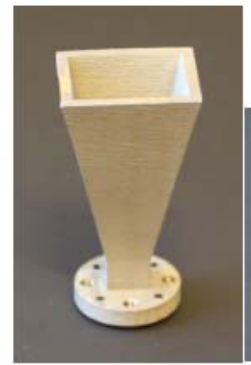

(a)

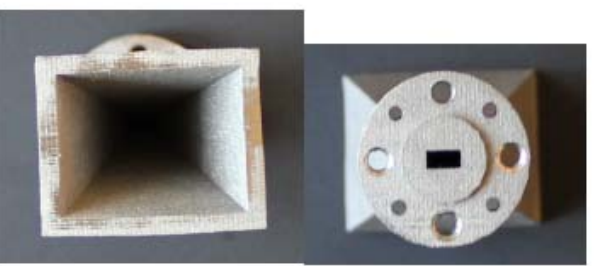

(b) (c)
Fig. 2. Photographs of the 3D printing pyramidal horn antenna: (a) profile view, (b) aperture view and (c) flange view.

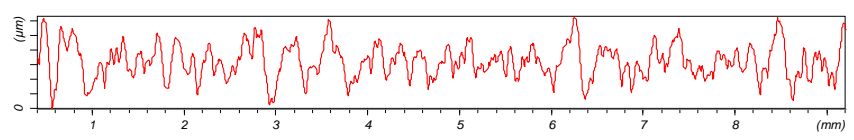

Fig. 3 Measured surface roughness of the antenna $\mathrm{Ra}=7.69 \mu \mathrm{m}$, standard deviation $1.321 \mu \mathrm{m}$.

\section{Simulated And Measured Antenna Performance}

The full-wave finite element method (FEM) based software Ansoft HFSS is used to simulate the antenna. The measurement results were obtained in the anechoic chamber under a far-field setup at Télécom Bretagne. Fig. 4 shows the simulated and measured performance of the conical horn antenna. In Fig. 4 (a), the $\left|\mathrm{S}_{11}\right|$ is below $-8 \mathrm{~dB}$ across the whole V-band, the matching could be improved if a taper is adopted between the rectangular feeding waveguide and the conical horn. The measured $\left|\mathrm{S}_{11}\right|$ agrees with the simulation behaviorally. In Fig. 4 (b) the simulated gain is larger than $19 \mathrm{dBi}$ in band and the maximum gain is $21.3 \mathrm{dBi}$ at $65 \mathrm{GHz}$, while in measurement the gain is larger than $18 \mathrm{dBi}$ in band and the maximum gain is $21 \mathrm{dBi}$ at $69 \mathrm{GHz}$. The difference is caused by fabrication tolerance like the $7.7 \mu \mathrm{m}$ surface roughness and $\pm 5 \%$ dimensional control. In Fig. 4 (c) and (d) the co-polarized radiation patterns agree well between simulation and measurement on both E- and H-planes. The cross-polarization increases from $-60 \mathrm{~dB}$ to $-20 \mathrm{~dB}$. This is because of the limited dynamic range of the measurement setup and fabrication tolerance. Though the cross-polarization deteriorates in measurement, it is still acceptable for practical usage. Moreover, the $-20 \mathrm{~dB}$ cross-polarization is comparable with the $-20 \sim-30 \mathrm{~dB}$ cross-polarization level of most V-band commercial horns of $20 \mathrm{dBi}$ gain.

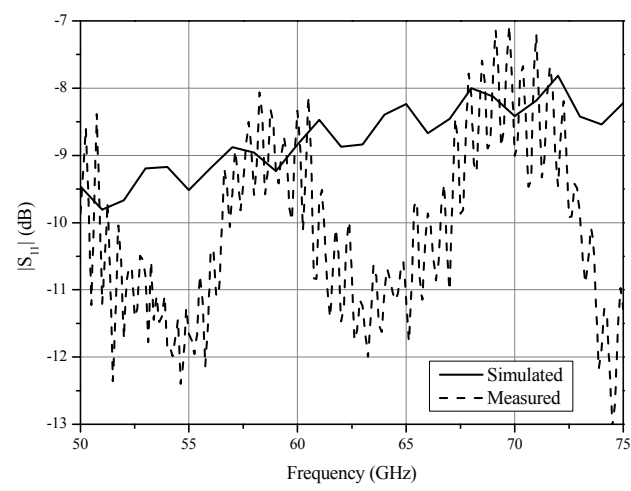

(a)

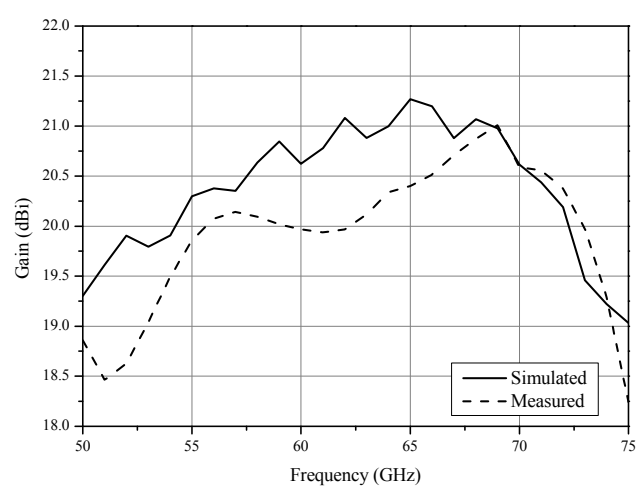

(b)

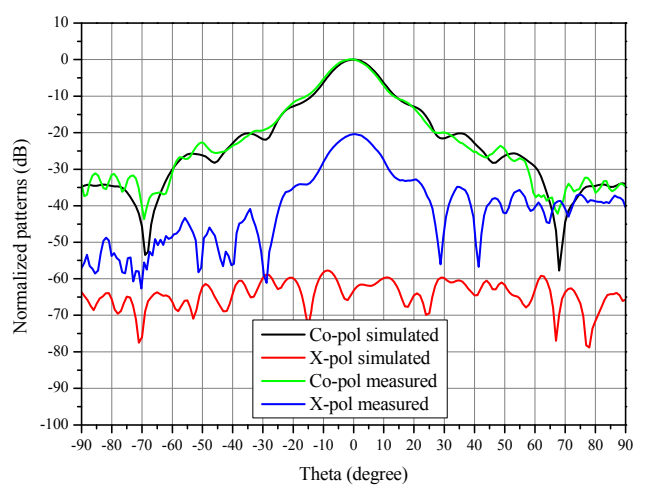

(c) 


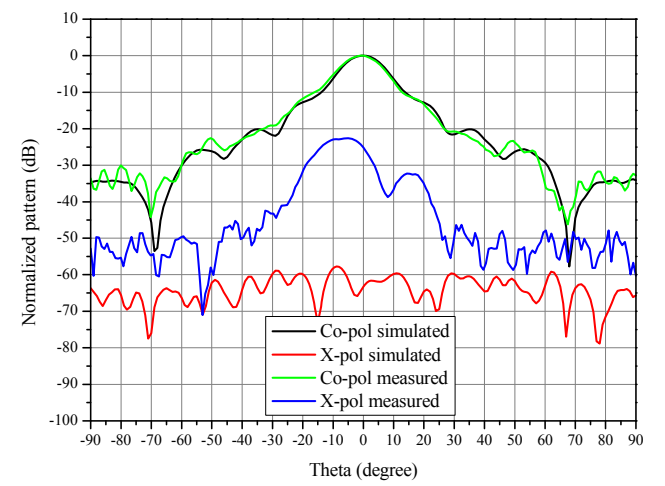

(d)

Fig. 4. Performance of the 3D printing conical horn antenna: (a) $\left|\mathrm{S}_{11}\right|$, (b) gain, radiation patterns at $60 \mathrm{GHz}$ : (c) E- and (d) H-plane.

Fig. 5 shows the simulated and measured performance of the pyramidal horn antenna. In Fig. 5 (a), the $\left|S_{11}\right|$ is below $-20 \mathrm{~dB}$ across the whole band. The antenna has in-band gain larger than $18.5 \mathrm{dBi}$ with the maximum gain of $22.2 \mathrm{dBi}$ at $75 \mathrm{GHz}$, while the measured gain is typically $0.5 \mathrm{~dB}$ less than the simulated values and the maximum gain is $22.3 \mathrm{dBi}$ at $72 \mathrm{GHz}$. The difference is caused by fabrication tolerance and surface roughness. In Fig. 5 (c) and (d), the co-polarization agrees well on E- and H-planes, while the cross-polarization deteriorates from $-60 \mathrm{~dB}$ to $-25 \mathrm{~dB}$. This is caused by the limited dynamic range of the measurement setup and the fabrication tolerance.

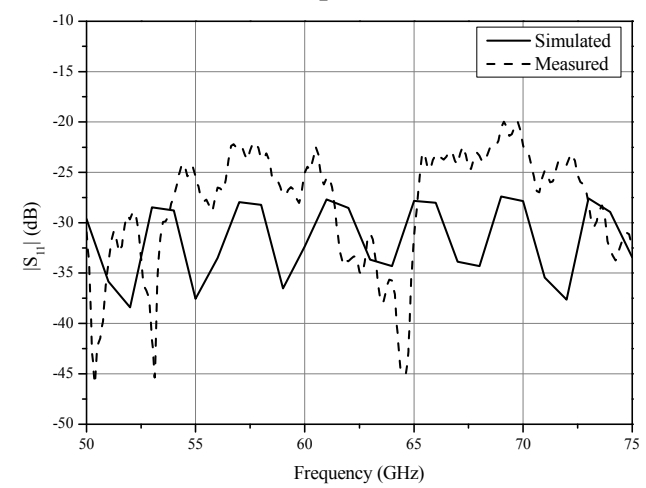

(a)

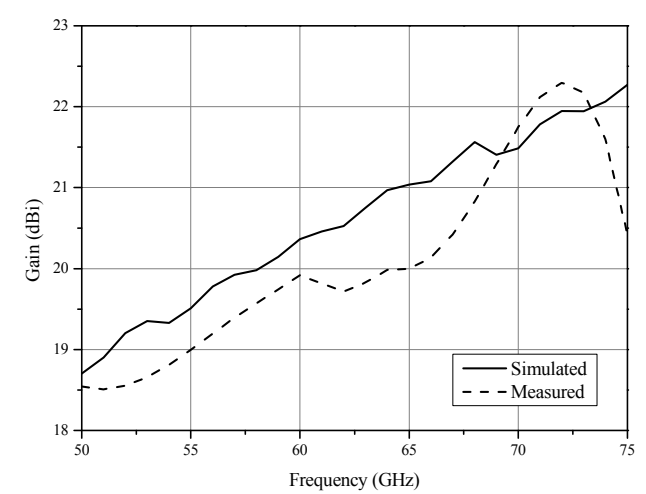

(b)

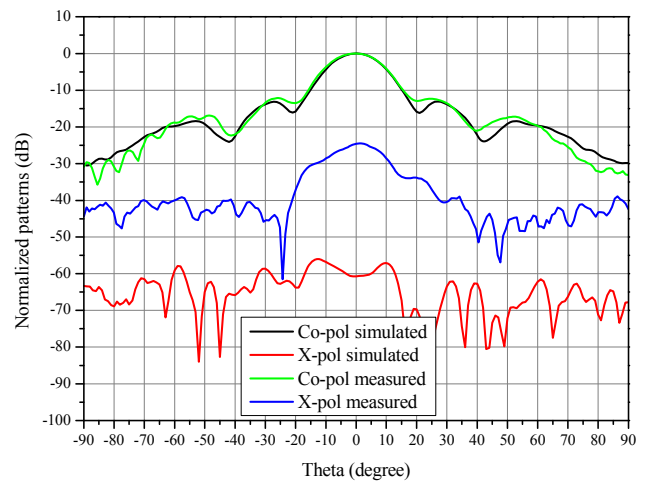

(c)

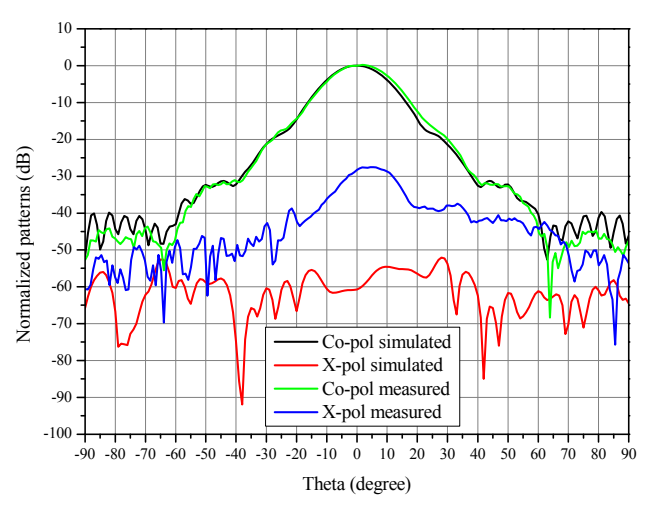

(d)

Fig. 5 Performance of the 3D printing pyramidal horn antenna: (a) $\left|S_{11}\right|$, (b) gain, radiation patterns at $60 \mathrm{GHz}$ : (c) E- and (d) H-plane.

\section{CONCLUSIONS}

The metallic 3D printing technology has been used and evaluated for mmWave antenna implementations. 316L stainless steel is used to fabricate the conical and pyramidal horn antennas. $\pm 5 \%$ dimensional tolerance and $7.7 \mu \mathrm{m}$ surface roughness with $1.3 \mu \mathrm{m}$ standard deviation are detected. Agreement between simulation and measurement is achieved. The measured performance is comparable with commercial horns. Comparing with traditional milling and injection moulding, the 3D printing technology proves its great potential for wide-spread applications in the mmWave range.

\section{ACKNOWLEDGEMENT}

The author acknowledges the funding support from Swedish Foundation for Strategic Research (SSF) through the program of 'RFIC solution s for very high data rate, energy and spectrum efficient wireless $\mathrm{THz}$ communication', Swedish Research Council (VR) through the program of 'Gigabits at $\mathrm{THz}$ frequencies', and the Visiting Scientist Program 'Packaged antenna in LTCC technology for mm-wave single chip transceivers' from Télécom Bretagne-Institute Mines-Télécom. Acknowledgement is also given to Raymond Jezequel from Télécom Bretagne-Institute Mines-Télécom; Yinggang Li, 
Mingquan Bao, Ola Tageman and Thomas Emanuelsson from Ericsson; Stephan Thundal from Arcam; Hans Kimblad from Digital Metal for all their support.

\section{REFERENCES}

[1] I. Gibson, D. W. Rosen, and B. Stucker, "Additive manufacturing technologies: rapid prototyping to direct digital manufacturing," Springer-Verlag, USA, 2010

[2] H. Lipson and M. Kurman, "Fabricated: the new world of 3D printing," Wiley, USA, 2013.

[3] B. Zhang, D. Titz, F. Ferrero, C. Luxey, and Y. P. Zhang, "Integration of quadruple linearly-polarized microstrip grid array antennas for $60-\mathrm{GHz}$ antenna-in-package applications," IEEE Trans. Comp. Packag. Manuf. Technol., vol. 3, no. 8, pp. 1293-1300, Aug. 2013.

[4] B.Zhang, Y. P. Zhang, D. Titz, F. Ferrero, and C. Luxey, "A circularly-polarized array antenna using linearly-polarized subgrid arrays for highly-integrated radio," IEEE Trans. Antennas. Propag, vol. 61, no. 1, pp. 436-439, Jan. 2013.

[5] B. Zhang, L. Wei, and H. Zirath, "A D-band packaged antenna on low temperature co-fired ceramics for wire-bond connection with an indium phosphide power meter," in Proc. Int. Symp. Antennas Propag., (ISAP2013), Nanjing China, Oct. 2013, pp. 637-640.

[6] B. Zhang, H. Gulan, T. Zwick, Y. Li, U. Oderfält, F. Carlsson, and H. Zirath, "Integration of a $140 \mathrm{GHz}$ packaged LTCC grid array antenna with an InP detector," IEEE Trans. Comp. Packag. Manuf. Technol.(in press).

[7] E. G. Geterud, P. Bergmark, and J. Yang, "Lightweight waveguide and antenna components using plating on plastics," in Proc. Euro. Conf. Antennas Propag., (EuCAP2013), Gothenburg Sweden, Apr. 2013, pp. 1812-1815.

[8] C. R. Garcia, R. C. Rumpf, H. H. Tsang, and J. H. Barton, "Effects of extreme surface roughness on 3D printed horn antenna," Electron. Lett., vol. 49, no. 12, pp. 734-736, Jun. 2013. 